\title{
Outcome of upper respiratory tract infections in healthy children: Antibiotic stewardship in treatment of acute upper respiratory tract infections
}

\author{
Ejaz Ahmed Khan ${ }^{1}$, Mazhar Hussain Raja², Shehla Chaudhry³, \\ Tehreem Zahra ${ }^{4}$, Salman Naeem ${ }^{5}$, Masuma Anwar ${ }^{6}$
}

\begin{abstract}
Objective: The objective of the study was to assess the outcome of upper respiratory tract infections (URTI) in healthy children.

Methods: This descriptive study was conducted on 314 children aged 3-36 months in the paediatric outpatient clinic and emergency department with symptoms of URTI (fever, cough, rhinorrhoea) for $\leq 5$ days. Patient's demographics, clinical features, laboratory data and outcome were recorded. Follow up phone calls were made to parents on day 7 (response 93.6\%) and day 14 (response 94.6\%) to record outcome. Results: A total of 314 children with URTls were included. Majority (57.6\%) were males and <1year of age (40\%). Common manifestations of URTI were fever (89\%), cough (79\%), rhinorrhoea (62\%), pharyngitis $(79 \%)$ and conjunctivitis (46\%). More than half (53\%) had history of contact with URTI in a family member. Mean duration of symptoms was $2.7 \pm 1.3$ days. Majority $(93 \%)$ of children were given supportive treatment and only $6.7 \%$ received antibiotics initially. Most of children (76\%) recovered within one week and $91.8 \%$ within two weeks with supportive care only. Only $4 \%$ children were hospitalized and $12 \%$ required follow up visit of which $16 \%$ needed oral antibiotics. Complications or deaths did not occur.

Conclusions: Majority of URTIs in healthy children resolved with supportive treatment and do not require antibiotics. Antibiotic stewardship in simple URTIs should be practiced using awareness and advocacy campaigns.
\end{abstract}

KEYWORDS: Upper respiratory tract infections, Children, Antibiotics, Antibiotic stewardship.

doi: https://doi.org/10.12669/pjms.36.4.1420

How to cite this:

Khan EA, Raja MH, Chaudhry S, Zahra T, Naeem S, Anwar M. Outcome of upper respiratory tract infections in healthy children: Antibiotic stewardship in treatment of acute upper respiratory tract infections. Pak J Med Sci. 2020;36(4):642-646. doi: https://doi.org/10.12669/pjms.36.4.1420

This is an Open Access article distributed under the terms of the Creative Commons Attribution License (http://creativecommons.org/licenses/by/3.0), which permits unrestricted use, distribution, and reproduction in any medium, provided the original work is properly cited.

1. Ejaz Ahmed Khan, MBBS, MD.

Department of Pediatrics,

2. Mazhar Hussain Raja, MRCP, MRCPC.

Department of Pediatrics,

3. Shehla Chaudhry, FCPS.

Department of Pediatrics,

4. Tehreem Zahra, MBBS.

Department of Pediatrics,

5. Salman Naeem, MBBS.

Department of Emergency Medicine,

6. Masuma Anwar MBBS.

Department of Pediatrics,

1-6: Shifa International Hospital Ltd, Shifa Tameer-e-Millat University, Islamabad, Pakistan 44000.

Correspondence:

Ejaz A. Khan, MD

Email: ejazkhan99@hotmail.com

* Received for Publication:

July 24, 2019

* $1^{\text {st }}$ Revision Received:

* $2^{\text {nd }}$ Revision Received:

* Final Revision Accepted:
July 27, 2019

February 17, 2020

February 19, 2020

\section{INTRODUCTION}

Upper respiratory tract infection (URTI) is one of the most common childhood illnesses with mostly an acute, self-limited course. ${ }^{1,2}$ It is caused by a variety of infectious agents but mostly respiratory viruses $(61 \%){ }^{2}$ Rhinoviruses, respiratory syncytial virus (RSV), influenza viruses, parainfluenza viruses and adenoviruses are commonly responsible for URTIs in preschool children accounting for at least $50 \%$ of colds in both children and adults with admission in 180 per 10,000 children. $^{2}$

Diagnosis of URTI is made on clinical grounds. Laboratory tests are usually not needed in healthy children with uncomplicated URTI. However, rapid viral testing (direct 
immunofluorescent-antibody staining) and reverse transcriptase-PCR may be done for rapid diagnosis in emergency rooms and sometimes in outpatient clinics. Most of these children recover completely. Antibiotics are indicated for specific diagnosis such otitis media or sinusitis if associated or follow URTI.

The use of antibiotics in URTI is very common despite the self-limiting nature of most viral infections. ${ }^{3} \quad$ Antibiotic stewardship principal dictates that antibiotics should not be used in these viral infections in children and adults. ${ }^{4,5}$ Antibiotic stewardship is a "collective set of strategies to improve the appropriateness and minimize the adverse effects of antibiotic use, decrease resistance, toxicity and costs and to promote the selection of the optimal antibiotic regimen, dose, duration and route of administration". In Pakistan URTI epidemiology in children has not been well documented. Only few studies exist related to influenza, respiratory viruses, severe pneumonia and bronchiolitis.6-8 Unfortunately up to $70 \%$ of patients with URTI antibiotics are prescribed. ${ }^{9}$ This clinical study aims to assess the outcome of URTIs in healthy children and to discourage the inappropriate use of antibiotics.

\section{METHODS}

This is a descriptive study conducted at Department of Pediatrics, Shifa International Hospital from January 2014 to February 2015 after approval from Institutional Review Board and Ethics Committee (Ref: IRB\# 329-178-2014 dated January 23, 2014). All healthy children (age 3-36 months) presenting in Pediatrics outpatient clinic and emergency department with symptoms of URTI (including fever, cough, rhinorrhea) for $\leq 5$ days were enrolled in the study after written informed consent from the parents. Patients were given treatment as per standards and at the discretion of their respective paediatricians, which included supportive treatment such as antipyretics, nebulization, saline nasal irrigation and to increase fluids. Counselling was given for the selflimiting course of URTI, specific indications for antibiotic use and to return if there is deterioration. Hospitalization, antibiotics or investigations were done in selected cases only. Follow-up phone calls were made to parents on day 7 (response 93.6\%) and day 14 (response 94.6\%) to record outcome. Outcome variables included \% of children given or discontinuing antibiotics, $\%$ requiring hospitalization or laboratory evaluation, $\%$ children with resolution of symptoms on day 7 and 14 .
The sampling technique was purposive and consecutive. Sample size of $314(335 \pm 10 \%)$ was calculated by taking 0.05 at $95 \%$ confidence level, 0.05 absolute precision, prevalence ${ }^{3}$ of $68 \%$ by using WHO sample size calculator.

Patients' demographic details, underlying illnesses, immunization history, and clinical features on examination, laboratory data and

Table-I: Demographics and clinical characteristics of children with URTI in 314 children.

\begin{tabular}{|c|c|}
\hline Parameters & N (\%), Mean, Range \\
\hline Total & $314(100)$ \\
\hline $\begin{array}{l}\text { Demographics } \\
\text { - Males } \\
\text { - Age } \\
\text { - <1 years } \\
\text { - Mean age in months }\end{array}$ & $\begin{array}{c}124(39.5) \\
16.6 \pm 9.5(3-36)\end{array}$ \\
\hline $\begin{array}{l}\text { History } \\
\text { - Contact in the family } \\
\text { with viral URTI } \\
\text { - Fully Immunized }\end{array}$ & $\begin{array}{l}168(53.5) \\
309(98.4)\end{array}$ \\
\hline $\begin{array}{l}\text { Mode of visit } \\
\text { - Outpatient clinic } \\
\text { - Emergency Department }\end{array}$ & $\begin{array}{c}294(93.6) \\
20(6.4)\end{array}$ \\
\hline Mean documented temperature & $101.4 \pm 1.2^{\circ} \mathrm{F}(99-104)$ \\
\hline Mean duration of symptoms & $2.7 \pm 1.3$ days $(1-5)$ \\
\hline Presenting Symptoms & \\
\hline - Fever & $279(88.9)$ \\
\hline - Cough & $248(79)$ \\
\hline - Rhinorrhea & $194(61.8)$ \\
\hline - Anorexia / reluctance feed & 112 (35.7) \\
\hline - Vomiting & $77(24.5)$ \\
\hline - Disturbed sleep & $23(7.3)$ \\
\hline - Ear ache & $8(2.5)$ \\
\hline Physical Signs & \\
\hline - Erythema of pharynx & $249(79.3)$ \\
\hline - Conjunctivitis & 146 (46.5) \\
\hline - Rash & $17(5.4)$ \\
\hline - Rhonchi/crepitations & $3(1 \%)$ \\
\hline Associated Clinical diagnosis & \\
\hline - Otitis media & $17(5.4)$ \\
\hline - Croup & $12(3.8)$ \\
\hline - Bronchiolitis & $10(3.2)$ \\
\hline - Febrile seizures & $7(2.2)$ \\
\hline - Measles & $2(0.6)$ \\
\hline
\end{tabular}

URTI: upper respiratory tract infections. 
outcome were recorded. Demographics, clinical, features, management and outcome were presented as mean \pm standard deviation (SD) for quantitative variables or percentage for qualitative variables.

\section{RESULTS}

A total of 314 children with URTI were enrolled for the study. Majority were males, infants (<1year of age), had a history of contact with family member with URTI with common signs and symptoms of URTI (Table-I). On initial visit, majority (93.3\%) of children were given supportive treatment and only $6.7 \%$ required an antibiotic based on specific focus of infection (Table-II). Antibiotics were discontinued at presentation in $18.5 \%$ children with most commonly prescribed cefixime (41\%). Specific diagnoses were present in $17.5 \%$ children with otitis media in $31 \%$ that required an antibiotic and amoxicillin was the commonly prescribed antibiotic. A total of $11.8 \%$ children required a follow-up clinic visit with $78 \%$ having same symptoms and only $16 \%(6 / 37)$ required an antibiotic but of these $83 \%$ had recovered at the end of second week.

Only $3.8 \%$ children were hospitalized for persistent or worsening symptoms, unable to give treatment at home or due to parental anxiety (Table-II). Management included nebulization (saline with or without an inhaled bronchodilator), intravenous fluids, oxygen and mechanical ventilation. Empiric antibiotics were given to 8 children $(75 \%)$ and discontinued in $<72$ hours in $5(62.5 \%)$ of these children. The duration of hospitalization was $<2$ days in majority $(8 / 12,75 \%)$ of these children. Follow-up phone calls were not answered in $7.6 \%$ and $6.7 \%$ at first and second week respectively. At end of week one, $76 \%$ children had recovered completely; $24 \%$ had same or worsening symptoms. At the end of week two $91.8 \%$ children had recovered completely and only $8.2 \%$ had same or worsening symptoms. Overall only $8.6 \%$ children required an antibiotic for a specific diagnosis. Complications or death did not occur.

\section{DISCUSSION}

Our study found that in $92 \%$ of healthy children simple URTI resolved with supportive treatment only by second week of illness. Antibiotic were required in only approximately $9 \%$ of children with otitis media as being the commonest indication. Acute URTI in children are common with average of 8-10 episodes per year/child that resolve in majority without any specific therapy. ${ }^{1-3}$ Surveillance
Table-II: Management and outcome of children with URTI.

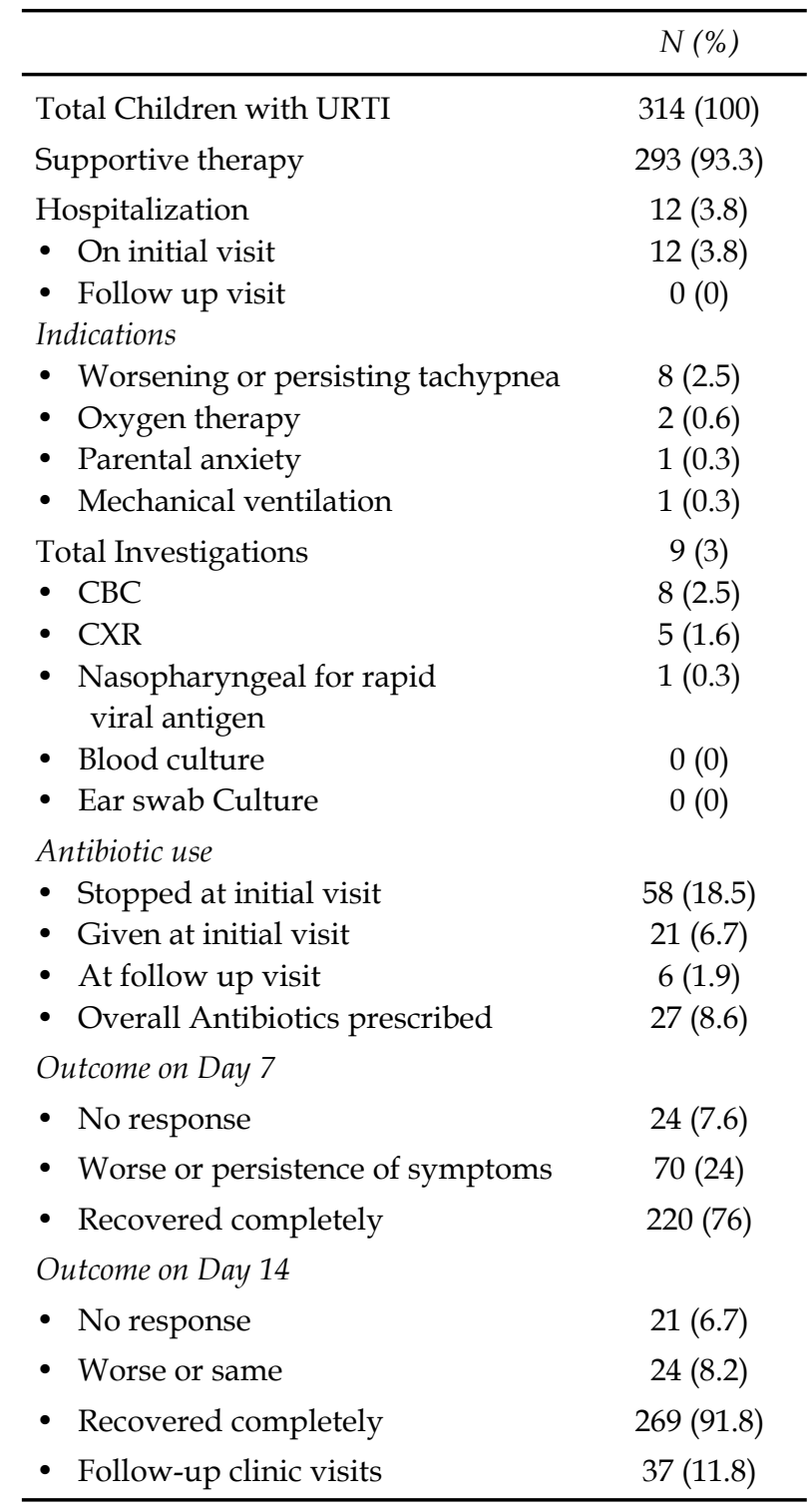

URTI: upper respiratory tract infections, CBC: complete blood count, CXR: chest $\mathrm{x}$-ray, OM: Otitis media

* Antibiotics given on initial presentation included amoxicillin in 17 (14 for $\mathrm{OM}$ ) and amoxicillin-clavulanate in 2 children (both OM).

** Antibiotics given on follow-up included amoxicillin in 3 (for $\mathrm{OM}$ ) and amoxicillin-clavulanate in 1 child.

studies from community, emergency visits and hospitalizations show the importance of various viral pathogens such as rhinoviruses, $R S V$, influenza viruses, parainfluenza viruses, and adenoviruses.

In Pakistan the exact etiology of URTIs has not been described. However a country-wide labbased surveillance system (children and adults) for influenza-like-illness and Severe Acute Respiratory 
Illness across Pakistan showed that influenza virus was detected in $24 \%$ samples ( $72 \%$ Influenza type A and $28 \%$ influenza type B viruses). ${ }^{6}$ A rural community-based prospective cohort active surveillance for respiratory viruses in infants $<2$ years old from Sindh showed different viral pathogens in $77.8 \%$ nasopharyngeal (enterovirus and rhinovirus (51.7\% infants), parainfluenza virus type III (8.3\%), and RSV (5.7\%). ${ }^{7}$ Another surveillance study of bronchiolitis and pneumonia in hospitalized $<2$ years old showed different viral pathogens in $75 \%$ cases (RSV 67\%: Influenza A: 24.5\%, Influenza B: 7\%, Adenovirus: $8.4 \%$ and human metapneumovirus: $5.2 \%){ }^{8}$

Clinically infants and children with URTI will present with a set of signs and symptoms lasting 7-14 days. ${ }^{1,2}$ Most of these children present with fever, cough, vomiting, rhinorrhoea and sore throat. Physical signs are non-specific, but may include clear to cloudy nasal discharge, conjunctivitis, oral ulcers and pharyngeal erythema. URTI has a higher prevalence during the fall and winter months as different viruses move through the community in a predictable manner such as the common cold. ${ }^{1}$ Many of these viruses may also cause other characteristic syndromes in children such as influenza like illness (influenza A and B), bronchiolitis (RSV), croup (Parainfluenza viruses), herpangina (coxsackie $A$ viruses) and pharyngoconjunctival fever (Adenoviruses) and some may require hospitalization.

Treatment of URTI is generally symptomatic with antipyretics, saline nasal irrigation, adequate hydration and a humidifier. Antihistamines, decongestants, antitussives, and expectorants, have not demonstrated any benefit. ${ }^{5}$ There is no justification for antibiotics in the treatment of URTI such as the common cold. ${ }^{3,5}$ American Academy of Pediatrics on Infectious Diseases has outlined some basic principles of antibiotic prescribing for URTIs in pediatrics including determining the likelihood of bacterial aetiology, weighing the benefits versus harm of antibiotics and implementing judicious antibiotic prescribing. ${ }^{4}$ However, million of antibiotic courses are dispensed in outpatient setting with at least 30\% of antibiotics prescribed being unnecessary.,

In Pakistan physicians including paediatricians continue to use antibiotics excessively in most URTIs. Pakistan has one of the highest $(62-70 \%$ of patients) prescription rate for antibiotics. ${ }^{10-12}$ This overuse and abuse was more common among general practitioners, public hospitals for costly antibiotics and $3^{\text {rd }}$ generation cephalosporins. ${ }^{12,13}$ Availability of over the counter antibiotics and selfmedication with mostly a broad-spectrum antibiotic for fever and sore throat is common in Pakistan. ${ }^{13}$ These broad-spectrum antibiotics are one of the main drivers of antibiotic resistance. In our study antibiotics given included broad-spectrum cefixime in $41 \%$ of children that were discontinued and given only supportive care. A questionnaire based study from Peshawar about use of antibiotics in children for common URTI showed that common practices seen were physician prescribed antibiotics (58\%), family recommendation $(27 \%)$, usefulness in fever or viral infections (35-25\%) and self-medication $(25 \%) .{ }^{14}$

The futility of antibiotics for self-limiting viral URTIs has been well documented. Guidelines for management of URTIs in children advocate selective use of antibiotics for conditions such as otitis media and sinusitis only. ${ }^{15,16}$ A non-Cochrane meta-analysis of 80 studies and a Cochrane systematic review of 10 high-quality randomized control trials showed only small benefit for acute otitis media in children. ${ }^{16}$ A Cochrane review of 27 trials on antibiotic use for sore throat also showed limited role for antibiotics. ${ }^{17}$ Antibiotic stewardship is a strategy to reduce the irrational antibiotic use in both inpatient and outpatient settings. ${ }^{18}$ It specifically can be used to control antibiotic use in URTIs such as common cold and pharyngitis. ${ }^{4,5,19}$ Other evidence about specific stewardship interventions that are well documented include communication skills, training and education..$^{20}$ One proven antibiotic stewardship strategy is delayed prescription. ${ }^{21} \mathrm{~A}$ delayed antibiotics strategy may significantly reduce unnecessary antibiotic use for respiratory infections such as otitis media. ${ }^{4}$

Antibiotics do not prevent secondary bacterial infection, may cause significant side effects and contribute to increasing antimicrobial resistance and costs. ${ }^{22}$ Awareness, education and training through campaigns about antibiotic stewardship must be done for all physicians at national level. A number of online antibiotic stewardship courses, including free courses, are available that may be used by clinicians and other healthcare workers to update and gain antibiotic stewardship skills. ${ }^{23,24}$ Vaccination and good infection control is also advocated for preventing transmission of the common viral illnesses. Simple practice of frequent hand washing, following cough etiquettes will lead to fewer illnesses and less need of antibiotics. Yearly administration of the influenza vaccine to prevent influenza infection and its complications will also help in curtailing the use of unnecessary antibiotics. ${ }^{25}$ 


\section{CONCLUSIONS}

Our study demonstrated that most healthy children with URTIs do not need any antibiotics and less need for hospitalization, investigations or follow-up visits without any adverse outcome. Antibiotic stewardship in simple viral URTIs should be practiced using educational awareness and advocacy campaigns for all practitioners at national level.

Acknowledgments: We would like to acknowledge the help of Miss Mehwish Rafiq for her help in our data analysis.

\section{Source of Funding: None.}

\section{Grant Support and Financial Disclosures: None.}

Conflict of Interests: No conflict of interests is declared by any of the authors.

\section{REFERENCES}

1. Alter SJ, Bennett JS, Koranyi K, Kreppel A, Simon R. Common childhood viral infections. Curr Probl Pediatr Adolesc Health Care. 2015;45(2):21-53. doi: 10.1016/j.cppeds.2014.12.001

2. Griffin MR, Walker FJ, Iwane MK, Weinberg GA, Staat MA, Erdman DD, et al. Epidemiology of respiratory infections in young children: insights from the new vaccine surveillance network. Pediatr Infect Dis J. 2004;23(11 Suppl):S188-192.

3. Fleming-Dutra KE, Hersh AL, Shapiro DJ, Bartoces M, Enns EA, File TM, et al. Prevalence of Inappropriate Antibiotic Prescriptions Among US Ambulatory Care Visits, 2010-2011. JAMA. 2016;315(17):1864-1873. doi: 10.1001/jama.2016.4151

4. Hersh AL, Jackson MA, Hicks LA, the Committee on Infectious Diseases. Principles of Judicious Antibiotic Prescribing for Upper Respiratory Tract Infections in Pediatrics. Pediatrics. 2013;132(6):1146-1154. doi: 10.1542/peds.2013-3260

5. Fashner J, Ericson K, Werner S. Treatment of the common cold in children and adults. Am Fam Phys. 2012;86(2):153-159.

6. Badar N, Bashir Aamir U, Mehmood MR, Nisar N, Alam MM, Kazi BM, et al. Influenza virus surveillance in Pakistan during 2008-2011. PloS One. 2013;8(11):e79959. doi: 10.1371/journal. pone.0079959

7. Ali A, Akhund T, Warraich GJ, Aziz F, Rahman N, Umrani FA, et al. Respiratory viruses associated with severe pneumonia in children under 2 years old in a rural community in Pakistan. J Med Virol. 2016;88(11):1882-1890. doi: 10.1002/jmv.24557

8. Bashir U, Nisar N, Arshad Y, Alam MM, Ashraf A, Sadia $\mathrm{H}$, et al. Respiratory syncytial virus and influenza are the key viral pathogens in children $<2$ years hospitalized with bronchiolitis and pneumonia in Islamabad Pakistan. Arch Virol 2017;162(3):763-773. doi: 10.1007/s00705-016-3146-7

9. The World Medicines Situation [Internet]. [cited 2019 Apr 3]. Available from: http://apps.who.int/medicinedocs/en/d/Js6160e/

10. Siddiqi S, Hamid S, Rafique G, Chaudhry SA, Ali N, Shahab $\mathrm{S}$, et al. Prescription practices of public and private health care providers in Attock District of Pakistan. Int J Health Plann Manage. 2002;17(1):23-40. doi: 10.1002/hpm.650

11. Amin A, Khan MA, Azam SMF, Haroon U. Review of prescriber approach towards rational drug practice in hospitalised patients. J Ayub Med Coll Abbottabad JAMC. 2011;23(1):19-22.

12. Khan MS, Ahmed Z, Jehan S, Fasseh-uz-Zaman null, Khan $\mathrm{S}$, Zaman $\mathrm{S}$, et al. Common trend of antibiotics usage in a tertiary care hospital of Peshawar, Pakistan. J Ayub Med Coll Abbottabad. 2010;22(1):118-120.
13. Ali AS, Ahmed J, Ali AS, Sonekhi GB, Fayyaz N, Zainulabdin $\mathrm{Z}$, et al. Practices of self-medication with antibiotics among nursing students of Institute of Nursing, Dow University of Health Sciences, Karachi, Pakistan. J Pak Med Assoc. 2016;66(2):235-237.

14. Siddiqui S, Cheema MS, Ayub R, Shah N, Hamza A, Hussain S, et al. Knowledge, attitudes and practices of parents regarding antibiotic use in children. J Ayub Med Coll Abbottabad. 2014;26(2):170-173.

15. Shields MD, Bush A, Everard ML, McKenzie S, Primhak R, British Thoracic Society Cough Guideline Group. BTS guidelines: Recommendations for the assessment and management of cough in children. Thorax. 2008;63(Suppl 3):iii115. doi: $10.1136 /$ thx.2007.077370

16. Glasziou PP, Del Mar CB, Sanders SL, Hayem M. Antibiotics for acute otitis media in children. Cochrane Database Syst Rev. 2004;(1):CD000219. doi: 10.1002/14651858.CD000219.pub2

17. Spinks A, Glasziou PP, Del Mar CB. Antibiotics for sore throat. Cochrane Database Syst Rev. 2013;(11):CD000023. doi: 10.1002/14651858.CD000023.pub4

18. Dellit TH, Owens RC, McGowan JE, Gerding DN, Weinstein RA, Burke JP, et al. Infectious Diseases Society of America and the Society for Healthcare Epidemiology of America guidelines for developing an institutional program to enhance antimicrobial stewardship. Clin Infect Dis Off Publ Infect Dis Soc Am. 2007;44(2):159-177. doi: 10.1086/510393

19. Randel A, Infectious Disease Society of America. IDSA Updates Guideline for Managing Group A Streptococcal Pharyngitis. Am Fam Phys. 2013;88(5):338-340.

20. Zetts RM, Stoesz A, Smith BA, Hyun DY. Outpatient Antibiotic Use and the Need for Increased Antibiotic Stewardship Efforts. Pediatrics 2018;141(6):e20174124. doi: 10.1542/peds.2017-4124

21. Spurling GK, Del Mar CB, Dooley L, Foxlee R, Farley R. Delayed antibiotic prescriptions for respiratory infections. Cochrane Database Syst Rev. 2017;9:CD004417. doi: 10.1002/14651858. CD004417.pub5

22. Founou RC, Founou LL, Essack SY. Clinical and economic impact of antibiotic resistance in developing countries: A systematic review and meta-analysis. PloS One. 2017;12(12):e0189621. doi: 10.1371/journal.pone.0189621

23. WHO. Antimicrobial Stewardship: A competency-based approach [Internet]. Open WHO. [cited 2019 May 10]. Available from: https://openwho.org/courses/AMR-competency

24. Centre for Disease Control - Antibiotic Resistance, Antibiotic Stewardship, and Antibiotic Adverse Events [Internet]. [cited 2019 May 10]. Available from: https://www.train.org/ cdctrain/course/ 1075730

25. Norhayati MN, Ho JJ, Azman MY. Influenza vaccines for preventing acute otitis media in infants and children. Cochrane Database Syst Rev. 2017;10:CD010089. doi: 10.1002/14651858. CD010089.pub3

\section{Author's Contribution:}

EAK: Contributed to the initial conception and design of the manuscript. EAK, MHR, SC, TZ, SN \& MA: Did the acquisition and assembly of the clinical data and were responsible for revising the manuscript critically for important intellectual content. EAK, MHR \& SC: Contributed to the critical revision. EAK, MHR \& SC: Were responsible for designing, analyzing data, and revising the manuscript critically for important intellectual content. All authors contributed to writing and approval of the final version of the paper. 